\title{
Impacts of climate warming on maximum aviation payloads
}

\author{
Diandong Ren ${ }^{1} \cdot$ Robert E. Dickinson ${ }^{2} \cdot$ Rong Fu $^{3} \cdot$ Janet F. Bornman ${ }^{4,5} \cdot$ Weidong Guo $^{6}$. Song Yang ${ }^{7}$. \\ Lance M. Leslie ${ }^{8}$
}

Received: 20 August 2017 / Accepted: 22 April 2018 / Published online: 22 August 2018

(c) The Author(s) 2018

\begin{abstract}
The increasing importance of aviation activities in modern life coincides with a steady warming climate. However, the effect of climate warming on maximum aircraft carrying capacity or payload has been unclear. Here we clarify this issue using primary atmospheric parameters from 27 fully coupled climate models from the Coupled Model Inter-comparison Project 5 (CMIP5) archive, utilizing the direct proportionality of near-surface air density (NSAD) to maximum take-off total weight (MTOW). Historical (twentieth century) runs of these climate models showed high credibility in reproducing the reanalysis period (1950-2015) of NSAD. In particular, the model simulated trends in NSAD are highly aligned with the reanalysis values. This reduction in NSAD is a first order global signal, just as is the warming itself, that continues into the future. To examine the statistical significance of the density reduction, a t-test was performed for two 20-year periods 75 years apart (2080-2100 vs. 2005-2025), using the Representative Concentration Pathways (RCP) 8.5 emission scenario of the Intergovernmental Panel on Climate Change (IPCC). Most continental areas easily passed the test at a P-value of 0.05 . These future changes of NSAD will likely have significant economic impacts on the aviation industry. For these two 20-year periods that we examined, the most extreme changes are in the Northern hemisphere in high latitudes, i.e., a 5\% decrease in $M T O W$, or $\sim 8.5-19 \%$ (aircraft-dependent) reduction in payload. The global average change is about 1\%. For the busy North Atlantic Corridor (NAC), the reduction in $M T O W$ is generally greater than $1 \%$ and that of payload several times larger.
\end{abstract}

\section{Introduction}

Commercial airliners provide an environment-friendly means for transporting passengers and cargo (Section 7.4.1.2 of IPCC AR5; 2013). Possible effects of aviation on atmospheric constituents and climate have been thoroughly studied (IPCC 1999; Minnis et al. 1999; Sausen et al. 2005; Fichter

Electronic supplementary material The online version of this article (https://doi.org/10.1007/s00382-018-4399-5) contains supplementary material, which is available to authorized users.

Diandong Ren

rendianyun@gmail.com; Diandong.Ren@ curtin.edu.au

Robert E. Dickinson

robted@jsg.utexas.edu

$\triangle$ Janet F. Bornman

Janet.Bornman@murdoch.edu.au

1 School of Electrical Engineering, Computing and Mathematical Sciences, Curtin University, Perth, Australia

2 Jackson School of Geosciences, University of Texas at Austin, Austin, USA et al. 2005; Fu and Liou 1993; Stuber et al. 2006; Brasseur et al. 2016; Yi et al. 2012; Iwabuchi et al. 2012). However, the converse, i.e., the effects of climate warming on aviation, have not yet been rigorously studied. Only recently, Coffel and Horton (2015) examined the effects of extreme temperatures on aviation payloads. The maximum bulk take-off weight (MTOW) of an aircraft can be expressed as:

$$
M T O W=M T O W_{0} \times C_{f},
$$

3 JPL, UCLA, Pasadena, USA

4 Curtin Business School, Curtin University, Perth, Australia

5 School of Veterinary \& Life Sciences, Murdoch University, Perth, Australia

6 School of Atmospheric Sciences, Nanjing University, Nanjing, China

7 School of Atmospheric Sciences, Sun Yat-sen University, Guangdong Province Key Laboratory for Climate Change and Natural Disaster Studies, Guangzhou, China

8 School of Mathematical and Physical Sciences, University of Technology Sydney, Sydney, Australia 
where $M T O W_{0}$ is the $M T O W$ for some standard climate conditions and $C_{f}$ corrects for variations from those conditions. This paper investigates climate warming effects on the $C_{f}$, based on the fact that irrespective of the design (fixed wing or helicopters; jets or propellers), the MTOW is directly proportional to near-surface air density $(N S A D)$. The manufacturer specified $M T O W$, i.e., $M T O W_{0}$, which is primarily a function of structural factors (i.e. wing spar strength), climb performance factor (related to FAA regulation requirements), and some external factors, such as runway length and runway contamination, usually leaves sizable technical room for the type of aircraft of interest. For example, an aircraft, simply by taking off at a larger engine thrust or a higher attack angle, may take off with a bulk weight exceeding the $M T O W_{0}$. However, such modifications would violate FAA regulations and require higher maintenance costs. For the purpose of this study, we assume such changes are not made. The notation of Eq. (1) is adhered to in the follow discussion. We do not have access to industry specifications, as stated by Hane (2016). Fortunately, they are not needed for our purpose here.

Aircrafts are air-lifted, and the $M T O W$ can be expressed in a generic form as $M T O W=M \rho_{a}\left|\vec{V}_{0}\right|^{2}$, where $M$ denotes the airplane mechanical properties such as wing span area, attack angle and fuselage-wing interaction; $\rho_{a}$ is air density and $\left|\vec{V}_{0}\right|$ is aircraft take-off speed (the value reached right before turnover for the initial climbing stage). If the take-off speed also is considered an aircraft mechanical property, then air density is the sole environmental factor that is directly proportional to MTOW. It is further assumed that the unavoidable load (weight of the empty airplane) of existing aircraft is not reduced as a result of possible technological advances during this (twenty-first) century. Consequently, absolute changes in $M T O W$ from $C_{f}$ also are changes of effective payload.

In this study, a suitable invariant entity for studying climate warming effects on civil aviation is introduced (Sect. 2). For applications to take-off payload, near-surface (airport elevation) air density is the single most significant atmospheric parameter for lift-generation. Its variations are examined over the twentieth and twenty-first centuries (Sect. 3). For the period with re-analysis data (1950-present), the extent to which air density, simulated by 27 coupled general circulation models (CGCMs, Table 1), approached reality also was examined. Based on this analyses, the decrease in maximum payload is examined and the inter-model spread of the uncertainty assessed up to the year 2100 (Sect. 3). Modern climate has a clear footprint of human activity (IPCC 2013; Lewis and Karoly 2015). Because future human behaviour is highly unpredictable, the largest uncertainty in the degree of warming resides with the industrial emission of greenhouse gases (GHGs) and other pollutants in the atmosphere to which climate is sensitive. The future state of the climate will depend crucially on how much emission controls nations choose to impose. Emission scenarios (ESs) as used by the IPCC describe various possible future releases into the atmosphere of GHGs, aerosols, and other pollutants, and are input as boundary conditions by climate models. In the most recent IPCC assessment report (AR5), the driving scenario is in the form of representative concentration pathways (RCPs). In this study, the climate model outputs under the high, business as usual scenario RCP 8.5 (meaning that this rising radiative forcing pathway would lead to $8.5 \mathrm{~W} \mathrm{~m}^{-2}$ heating effects in 2100) were used.

\section{Data and methods}

At any moment, forces acting on airplanes include: (a) gravity, which is downward and proportional to the total mass of the aircraft; (b) pressure gradient force ( $p g f$ ) acting on the bottom and upper surfaces of the wings. The vertical component of $p g f$ is lift. The horizontal backward component of $p g f$ is called pressure drag; (c) frictional drag, which always acts in the opposite direction to aircraft motion; (d) thrust, as a forward vector, operates along the nozzle direction. Its magnitude is controlled by engine overall efficiency (mechanical efficiency multiplied by thermal efficiency); and (e) last but not least, the induced drag (shear stress) at the wing tips. At take-off stage, because there are accelerations in vertical and horizontal directions, the forces are not in balance. The vertical component of excessive thrust (vector thrust minus all types of drag) works in synergy with lift in dominating the overall gravity. Horizontally, thrust also dominates (is far-larger than) drags. The loss in lift due to climate warming might be compensated for by adjusting take-off performance by enlarging the pitch-up angle at the cost of passenger comfort or enlarging thrust regardless of consequent maintenance costs. In this study, all these technical aspects are assumed to be invariants and that aircrafts are operated according to the current FAA regulations (for, e.g., runway length, maximum pitch-ups and so forth). In addition, as a breathing thermal engine, the thrust also is sensitive to environmental warming. Actually, both drag and thrust are unfavourably affected by warming, and are directly proportional to air density (derivations not included here). Viewing effects from environmental warming from energy perspective, it is straightforward to obtain that $\rho\left|\vec{V}_{a}\right|^{2}$ is a suitable invariant entity (reference pressure $p^{*}$ ) for studying climate warming effects on civil aviation. The following analyses examines NSAD as the single most important atmospheric parameter relevant for estimating changes in effective payload with environmental warming. It might be 
simply estimated from readily available estimates of global surface temperature. However, our analysis finds that NSAD is spatially highly variable in space so such a simple estimate would not be very useful. Furthermore, variations in water vapour density are seen to significantly affect variations in NSAD.

Air density is derivable from air pressure, temperature and humidity (Holman 1980; Wallace and Hobbs 2006):

$\rho_{a}=P /\left[R_{d} T(1+0.608 q)\right]$,

where $P$ is air pressure $(\mathrm{Pa}), R_{d}$ is the dry air gas constant $(\sim 287 \mathrm{~J} / \mathrm{kg} / \mathrm{K}), T$ is air temperature $(\mathrm{K})$ and $q$ is specific humidity (g/g). To apply Eq. (2) to the near-surface level, atmospheric fields of pressure $\left(P_{s}\right)$, temperature $\left(T_{s}\right)$ and specific humidity $q_{s}$ at ground level are required. These parameters fortunately are primary outputs from the Coupled Model Intercomparison Project (CMIP, e.g., https://cmip.ucar.edu/; Taylor et al. 2012). The monthly climate model outputs were obtained from the IPCC Data Distribution Centre [data collected by the German Climate Computing Center (Deutsches Klimarechen zentrum, DKRZ)]; British Atmospheric Data
Centre (BADC); and the Program for Climate Model Diagnosis and Intercomparison (PCMDI), USA (http://www. ipcc-data.org/sim/gcm_monthly/AR5/Reference-Archi ve.html). For models providing multiple perturbation runs, only rlilpl runs are used. To examine whether the historical runs from the climate models were close to reality in their simulated air density, NCEP/NCAR reanalyses were used as observations. The monthly NCEP/NCAR reanalysis (Kistler et al. 2001) data were obtained from the Earth System Research Laboratory website:http://www.esrl.noaa.gov/ $\mathrm{psd} / \mathrm{data} / \mathrm{gridded} / \mathrm{data}$.ncep.reanalysis.pressure. html. Relative humidity provided by the reanalyses was converted into specific humidity before applying Eq. (2).

\section{Results and discussion}

The Earth's atmosphere is dominated by its inactive "dry" components. Since the total mass of these components is conserved, NSAD is closely related to the thickness of the atmosphere. With an increase of temperature, the primary
Fig. 1 Indication of global warming. $\mathbf{a}$ is the climatological elevation of the mass center (estimated based on NCEP/ NCAR 2.5 degree reanalyses for the period 1950-2015). Except for plateaux, which may lift mass center to $10 \mathrm{~km}$ asl, most places have a mass center at $\sim 5 \mathrm{~km}$ asl, which roughly follows a zonal distribution, with equatorial regions possessing higher elevations than Polar regions. As is the case of warming, the increase of the mass center $\mathbf{b}$ also is globally a 1 st order dominant signal. The changes in mass center have less of a geographical footprint and are globally more uniform than the climatology of the mass center. Only sporadic regions, such as over the Sahara desert and Northern China, have experienced a decrease in the mass center in the past half century

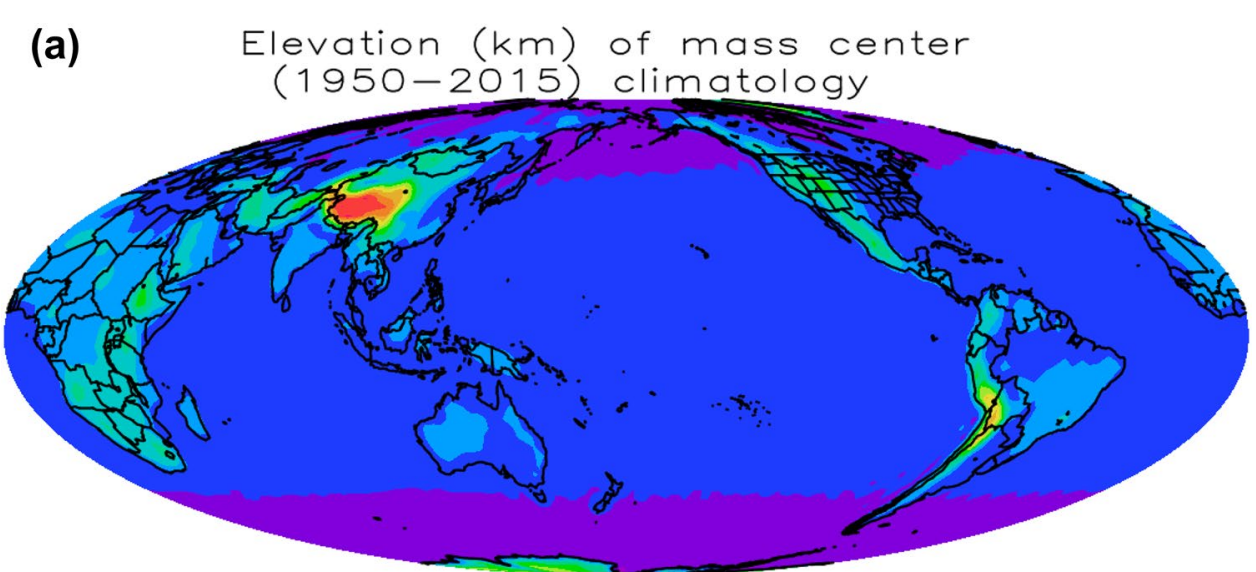

(b) Elevation change ( $m$ ) of mass center

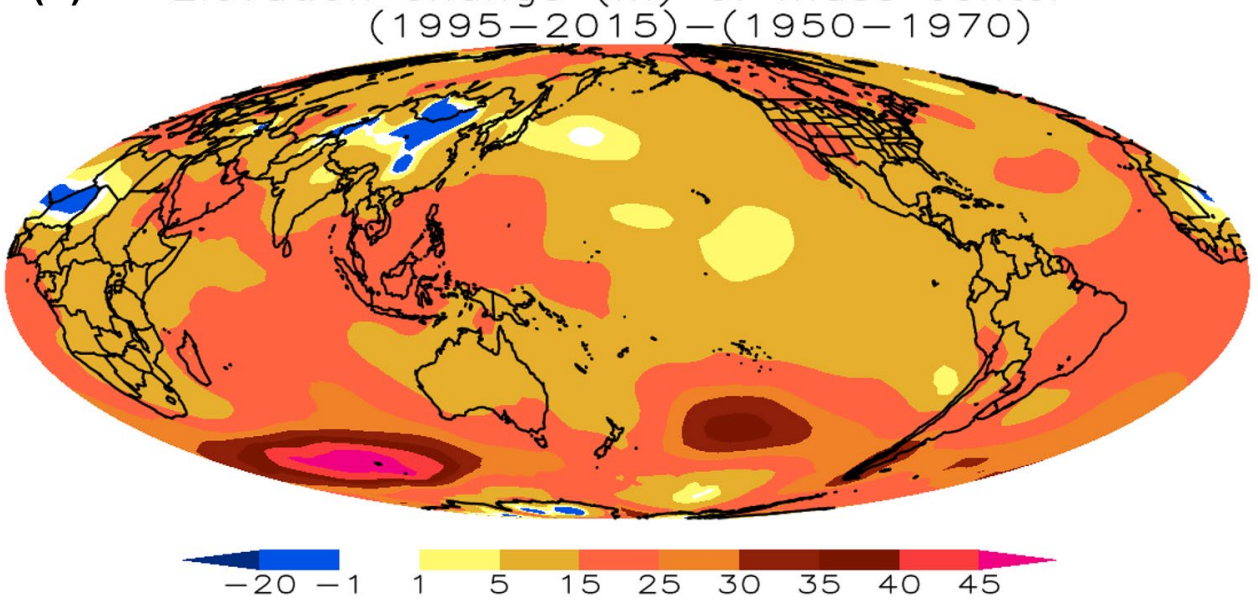


response is an expansion in volume and, subsequently, an increased/elevated mass centre. This can be seen clearly from Fig. 1. A close estimate of total air mass $\left(m_{\mathrm{e}}\right)$ is obtainable by integrating surface air pressure $\left(P_{s}\right)$ with respect to Earth surface area:

$$
m_{e}=R^{2} / g \int_{0}^{2 \pi} \int_{-\pi / 2}^{\pi / 2} P_{s} d \lambda d \sin (\varphi)
$$

where $R$ is the Earth radius $(\sim 6378 \mathrm{~km}), g$ is gravity acceleration $\left(\sim 9.8 \mathrm{~m} / \mathrm{s}^{2}\right), \lambda$ is longitude, and $\varphi$ is latitude.

At an arbitrary Earth surface location, the elevation of the $P_{s} / 2$ is considered the mass center of the air column. Figure 1a is the climatological (1950-2015 average) location of the mass center. Over oceanic areas (including the flat Oceanic continent), its distribution is largely zonal and the average elevation decreases from the equator $(\sim 5.5 \mathrm{~km})$ to the poles $(\sim 5 \mathrm{~km})$. Over plateaux, the mass center can be significantly raised. For example, over the Tibetan Plateau, with an average surface elevation of $4 \mathrm{~km}$ above sea level (asl) and surface pressure $\sim 600 \mathrm{hPa}$, the mass center can reach $10 \mathrm{~km}$ asl. Irrespective of the topographic disturbances, the mass center globally has increased significantly (Fig. 1b) during the past half century. On average, there is a $30 \mathrm{~m}$ lift. This thermally caused expansion is just one effective means for decreasing air density throughout the entire tropospheric atmosphere. An increase of lighter molecules (e.g., $\mathrm{H}_{2} \mathrm{O}$ has a smaller molar mass than $\mathrm{N}_{2}$ or $\mathrm{O}_{2}$, the dominant constituents of dry air) is another effective way of reducing air density. Although from the Clausius-Clapeyron Equation (Lawrence 2005), warm air has more capacity to hold moisture, it still is debatable whether the Earth's atmosphere actually gains mass, because the hydrological cycle also tends to intensify (Trenberth 2011; Allen and Ingram 2002; Held and Soden 2006), through facilitating inter-hemispherical moisture exchange (Khon et al. 2010) and destabilising local stratification profiles (Allen and Ingram 2002; Held and Soden 2006). According to Eq. (3), all existing reanalysis datasets show no statistically significant changes in global total air mass $\left(m_{e}\right)$ during their respective reanalysis period. This implies that the net water vapour input into the atmosphere is globally delicately balanced between geographic regions. Recent modelled and observed tropopause rise (Santer et al. 2003) is just one manifestation of the lift of mass center.

Applying Eq. (2) to the climate model simulated near surface pressure, temperature and humidity under the RCP 8.5 scenario, the ground level air density was estimated over the globe. Density variations over the years 1900-2100 for six global airports are shown in Fig. 2, as representatives. All 27 of the climate models (for clarity, only 24 are shown) unanimously indicated that the six sites experienced marked density decreases. Significant inter-model spread exists. However, it is noticeable that the spread started well before 1900 and should be ascribed to model systematic biases/ drifts (inherited from the preindustrial run initial conditions). On examining the near-surface temperature $\left(T_{s}\right)$, among the three primary parameters, against the NCEP/ NCAR reanalyses, it is apparent that significant bias corrections are required. For example, the MIROC5 simulated $T_{s}$ is $\sim 1.5^{\circ} \mathrm{C}$ lower than reality over the Greenland Ice Sheet. These biases in simulated air density are primarily ascribable to shifts in near-surface temperature. However, biascorrection seems unnecessary for this research, because the almost 'constant' shifts do not affect the trends, and hence our estimation of the relative decrease in NSAD. For each climate model, the amount of decrease in density easily exceeds the magnitude of the natural inter-annual variability. Geographically, NSAD over high latitude regions (e.g., Moscow) has larger inter-annual variability and also generally showed larger decreases over the simulated 200 years. For example, at Heathrow airport, NSAD had decreased at a rate of $\sim 0.15 \mathrm{~g} / \mathrm{m}^{3} /$ year during 1950-2015. The linear trends of decrease estimated based on the reanalyses (labelled red numbers on Fig. 2) are close to the model simulations (maximum and minimum values labelled on Fig. 2). The above analyses were done for all 27 climate models (for clarity, only 24 are shown in Fig. 2). Results from the other three (MPI-ESM-LR/MR and CanESM2) fall comfortably within the envelope of the ensemble of the air density trajectories.

Changes in air density are a gradual process over the years. To quantify the changes globally, average density was compared for the two 20-year periods: (2005-2025) and (2081-2100), as shown in Fig. 3, for HadGEM2-ES under the RCP 8.5 scenario. For the Northern hemisphere, in Polar regions, there can be more than a $5 \%$ decrease. The percentage changes over lower latitudes were found to be moderate. There is very high resemblance in spatial pattern among the 27 models. For example, the similarity is shown for 3 of the models (see Figs. S1-S3 for three additional models). Thus, the change in near-surface air density, just like the warming itself and the lift of the mass center of the atmosphere is a first order signal of climate change, in the recent past and well into the future. The reason we chose 2005-2025 as the period for comparison is that we estimate that the commercial aviation will likely peak during this period.

To quantitatively examine if the density changes were statistically significant, a t-test was performed over the two 20-year annual density time series (2005-2025) and (2081-2100). In Fig. 4, the t-value (right panels) and corresponding P-values (left panels, for a DoF of 38) are presented (6 climate models are shown to demonstrate this). Under the RCP 8.5 scenario, most global regions pass the $95 \%$ confidence interval. The signal to noise ratio is low 


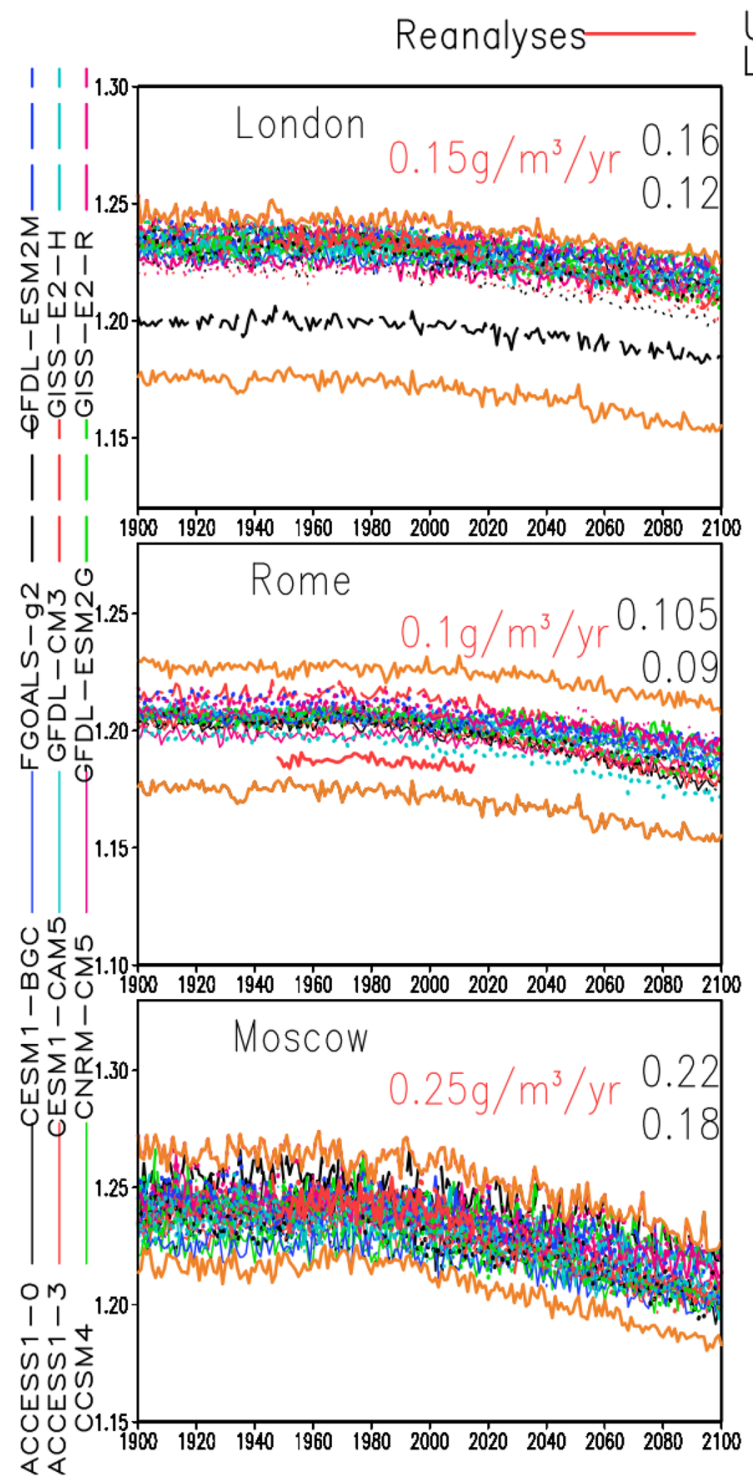

Fig. 2 Changes in near-surface air density for the period 1900-2100 as simulated by 24 climate models over six selected world airports. Near-surface air density estimated from NCEP/NCAR reanalyses are shown as red bold lines. The upper and lower bounds among the 24 climate models are shown as brown lines. Numbers in red are the linear trends estimated using the reanalyses period (1950-2015). The linear trends estimated by models over the same period have signifi-

only for very limited oceanic regions off the southern tip of Greenland and some sectors of the Southern Ocean. The oceanic region off southern Greenland collocates with the deep-water formation region of the North Atlantic meridional overturning circulation (MOC). Further investigation indicates that the lack of a decrease in density there is due to a weakened MOC that places less moisture into the atmosphere. Regionally, the air becomes drier and heavier. On

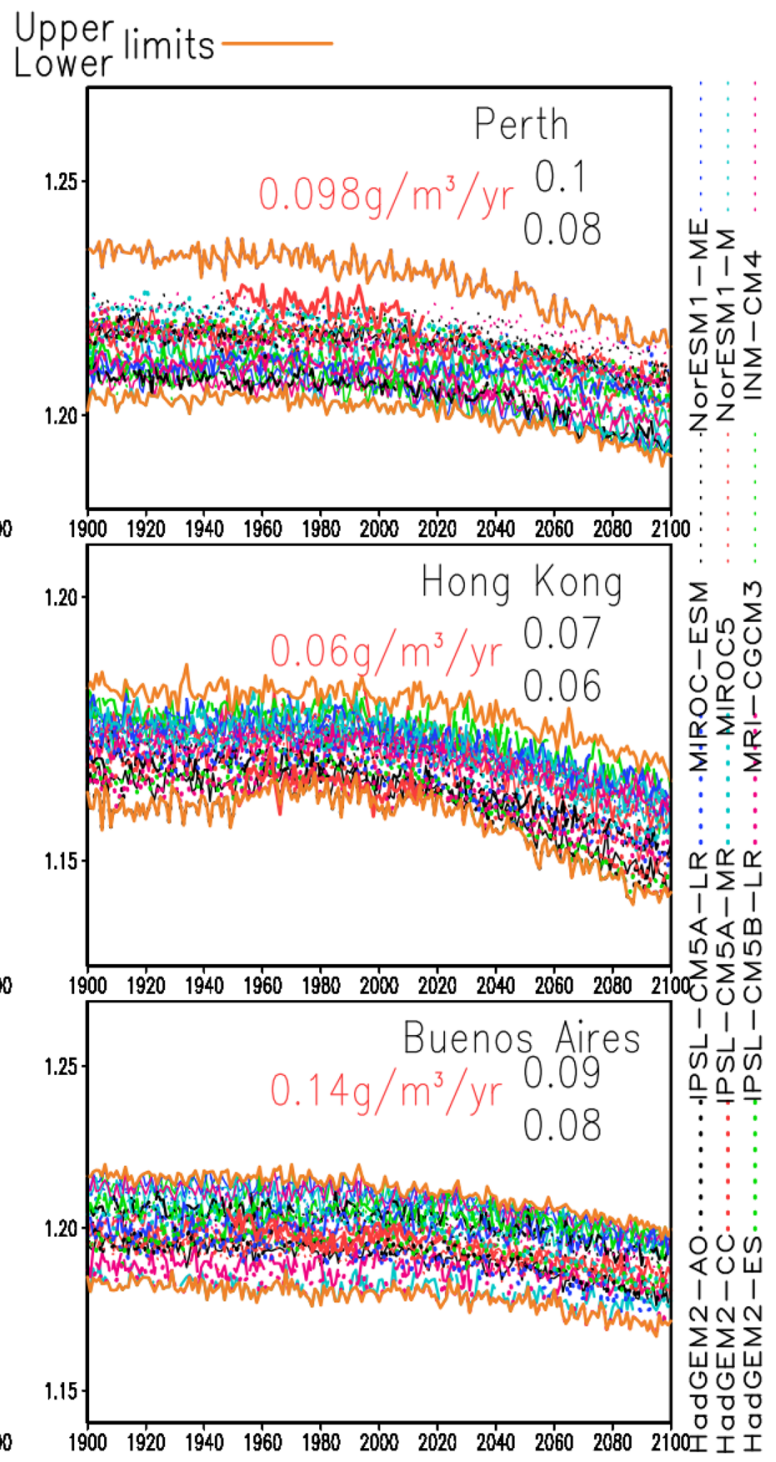

cant spread and the upper and lower limits are labelled (numbers in black). The analyses were performed on monthly data and averaged to annual values (actual plotted). As with all land-ocean-ice sheet fully coupled climate model outputs, the exact timing is hard to pinpoint. Only the statistical properties and long-term averages would resemble reality

the other hand, warming reduces the air density. These two cancelling factors make the net reduction in density small, hence statistically insignificant or, when the moistening effect wins out, may even increase the air density. For this study, the oceanic regions that did not pass the t-test can be disregarded, because very few airports are marine-based. Unlike the percentage changes, the tropical region, especially the Inter Tropical Convergence Zone (ITCZ, an area of 


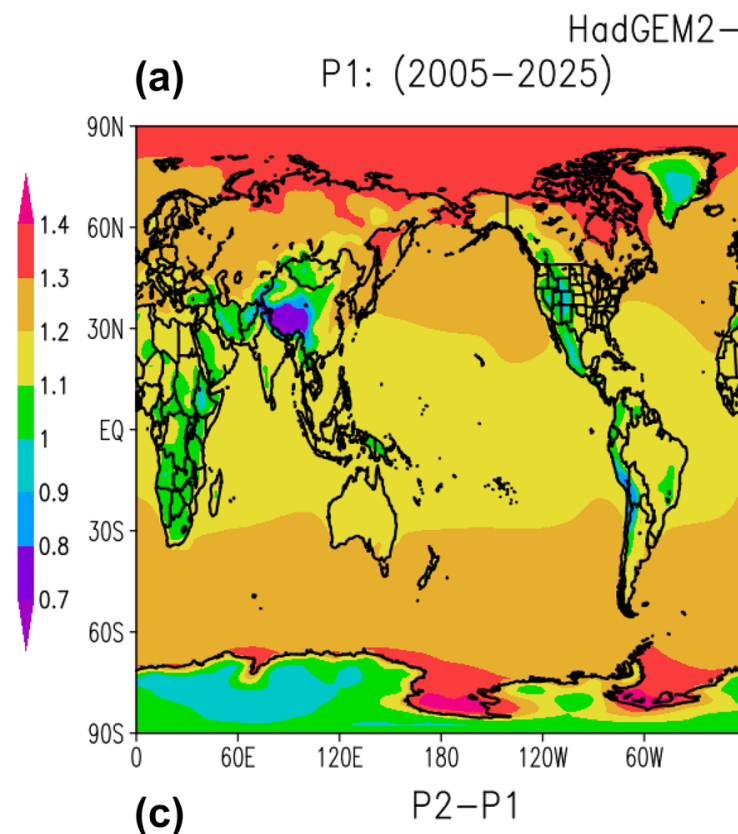

\section{(b) $\quad P 2:(2080-2100)$}
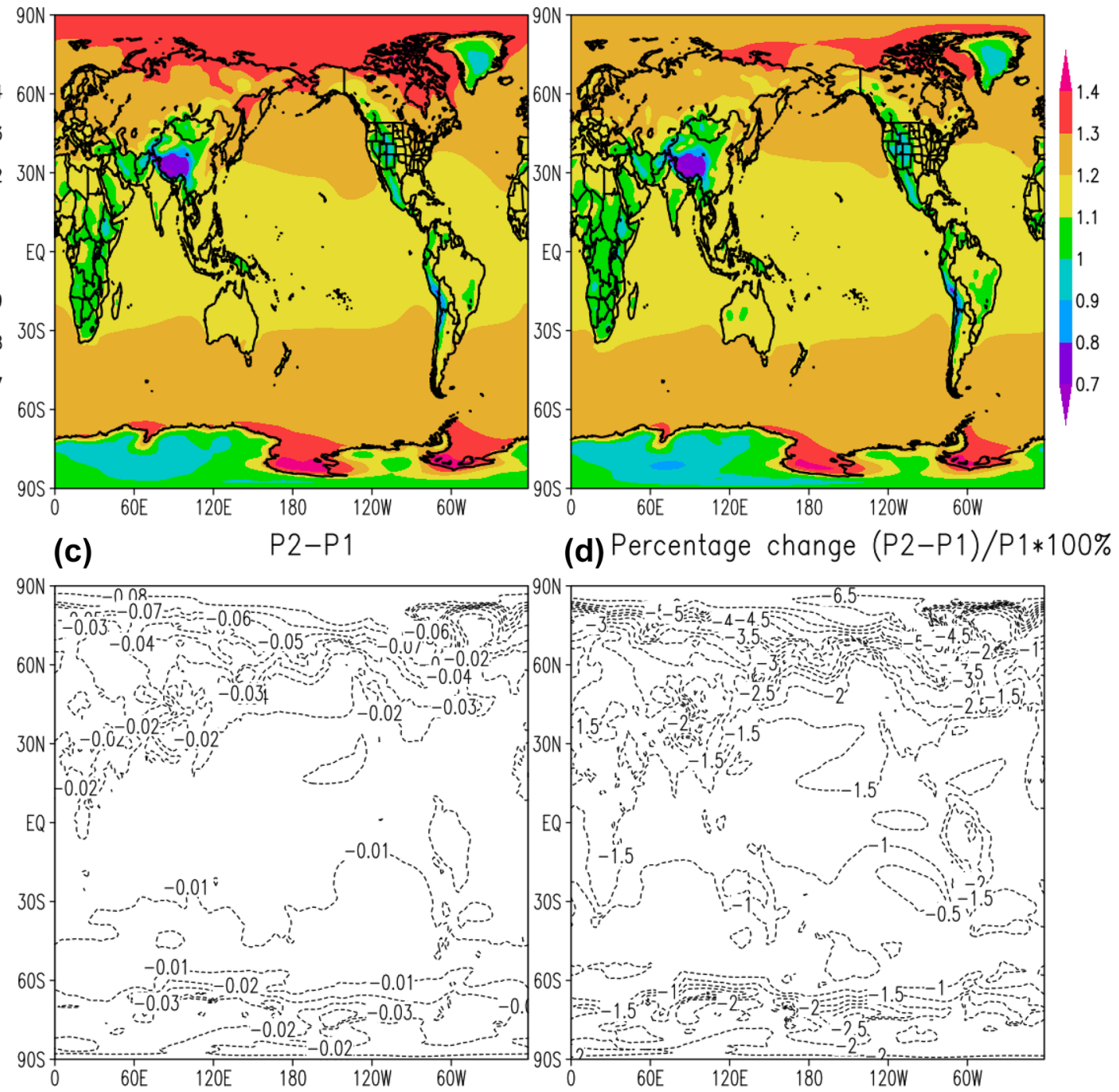

Fig. 3 HadGEM2-ES simulated near-surface air density $\left(\mathrm{kg} / \mathrm{m}^{3}\right)$ averaged over the two periods: a P1: (2005-2025) and b P2: (20812100 ), under the RCP 8.5 scenario assumption. The density differ-

low pressure and convergence of trade winds) had the lowest P-value, meaning that the changes over the region are most likely to be statistically significant. From Eq. (2), air density is co-controlled by temperature change and vapour content change. The temperature changes over tropical regions are smaller than over the high latitude regions. What make the changes over tropical regions statistically more significant are the relatively small changes in air density, for all time scales.

Although air density values simulated by the 27 climate models, when compared with those derived from the NCEP/ ences between these two periods are shown in $\mathbf{c}$, with corresponding percentage changes in $\mathbf{d}$

NCAR reanalyses, have systematic biases, the linear trends derived from models agree very well with the reanalyses. This indicates that for estimating payload decreases as the climate warms, the density time series can be normalized by their average value over a control period, say 1900-1920. For a specific model, differences in the values of the normalized density time series from unity are the percentage reductions of $N S A D$ and so MTOW (i.e., $C_{f}$ in Eq. (1)). If one further assumes an invariant unavoidable load (weight of an empty airplane), the decrease of MTOW also is the decrease of maximum payload. Air density changes estimated from 

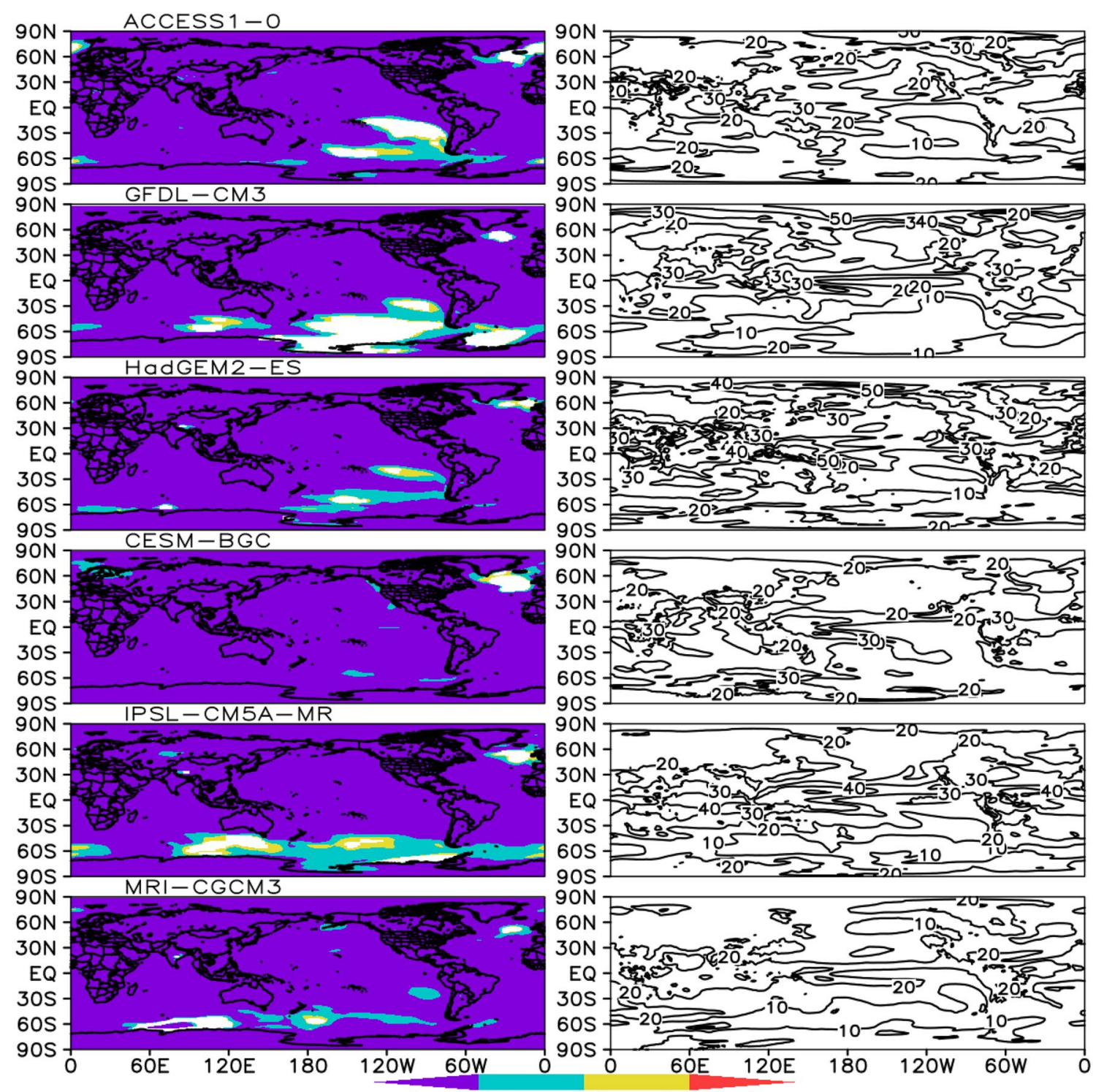

Fig. 4 Results from a t-test performed for near-surface air density (simulated under RCP 8.5 scenario) annual time series over two periods (2005-2025) and (2080-2100). Sophisticated modern climate models show consensus on the geographical patterns of the P-value (left panels) and t-values (right panels). Except for some oceanic regions off the southern tip of Greenland and some portions of the
Southern Oceans, most global regions passed the 95\% confidence interval, for a DoF of 38. Tropical regions, especially over the Inter Tropical Convergence Zone (ITCZ), experienced the most significant density decreases. The oceanic region off southern Greenland collocates with the region of deep-water formation of the North Atlantic meridional overturning circulation (MOC) all climate models were interpolated to the same spatial resolution as MRI-CGCM3. Figure 5 shows the MTOW changes between the two 20-year periods (2005-2025 and 2080-2100). The changes reach a $5 \%$ reduction for some high latitude and high elevation airports. For the busy North Atlantic Corridor (NAC), the reduction generally is greater than $1 \%$. This has important economic significance. For a Boeing 747-400, this means a net load reduction of about
3,969 $\mathrm{kg}$ (Table 2), approximately the passenger and luggage weight of $\sim 25$ passengers, or a $\sim 6 \%$ reduction in its full passenger carrying capacity. Actual payload equivalence of a $1 \%$ reduction in $M T O W$ for other types of aircraft is listed in Table 2. Because the ratio of unavoidable load to its maximum effective payload varies for different aircraft, the general reduction in net payload over the NAC varies from 5 to $8.3 \%$ for all the aircraft types considered. As mentioned, 
Percentage change of MTOW: (2080-2100) versus (2005-2025)

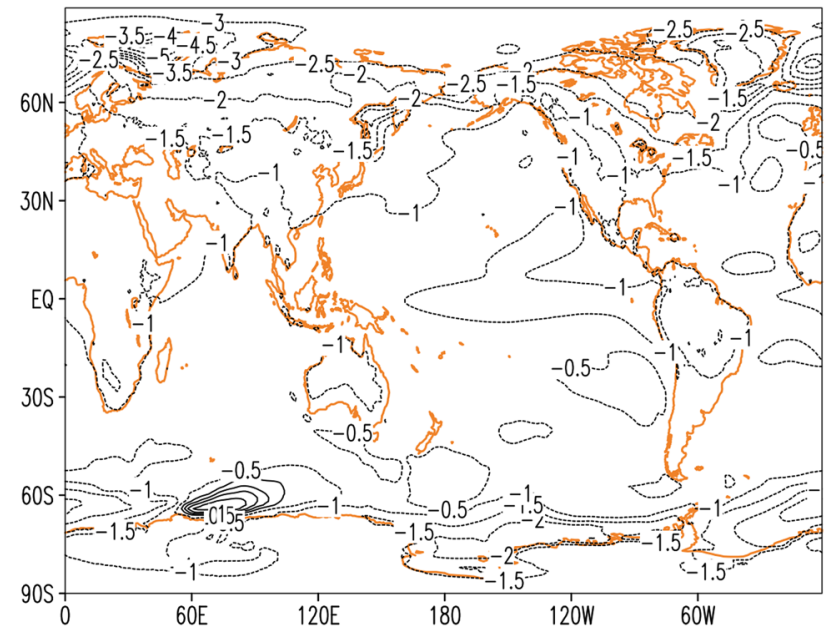

Fig. 5 The estimated ensemble mean decrease in aircraft maximum take-off total weight (MTOW), as a percentage, based on air density changes simulated by 27 climate models under the RCP 8.5 scenario. The near-surface density from each climate model was normalized by its mean value over 2005-2025 (the control period). Then a bilinear interpolation scheme was used to interpolate on to MRI-CGCM3's horizontal resolution. An ensemble average was taken over the climate models. The reduction can reach $5 \%$ over Northern Europe. For the North Atlantic Corridor (NAC), a 1\% reduction in MTOW was reached during the 75-year span

some Northern Hemisphere high latitude locations have a $\sim 5 \%$ decrease in NSAD and so MTOW. Considering that a $1 \%$ reduction in $M T O W$ corresponds to a $\sim 2 \%$ (for larger aircraft such as a Boeing 747-800 or an An-24) to 3.6\% (for small aircrafts such as an Embraer ERJ-145) reduction in effective payload, such a $\sim$ \% reduction in MTOW means a $\sim 8.5-19 \%$ reduction in effective payload year round. As we stated earlier, at the costs of extra maintenance, aircraft still can operate with the manufacturer labelled MTOW $\left(M T O W_{0}\right.$ in Eq. 1), under the unfavorable condition of reduced air density. There may be no apparent passenger or cargo reduction. However, there will be hidden extra costs, in addition to altering FAA regulations in specifying MTOW.

An important aspect of this research is that the modelling provides guidance as to the consequences for aviation for the climate scenario that may evolve by 2100 . Accordingly, we examined $N S A D$ derived from two intermediate scenario runs (RCP 4.5 and RCP 6.0) and found that the results, not surprisingly, differed only quantitatively from RCP 8.5 , as discussed above. It is noteworthy, however, that the more moderate the emission scenario, the smaller the decrease in NSAD. The degree in NSAD reduction with RCPs, as expected, is non-linear. There is a $2.5 \mathrm{Wm}^{-2}$ radiative forcing difference between RCP 8.5 and RCP 6.0 and only a $1.5 \mathrm{~W} \mathrm{~m}^{-2}$ difference between RCP 6.0 to RCP 4.5. The relative decreases in NSAD (over the 75 years previously defined), reveal that RCP 6.0 is closer to RCP 8.5 than it is to RCP 4.5. This strongly demonstrates that minimising the effects of global change is more effective if mitigation is implemented earlier. If the low (so called peak-and-then-decay RCP 2.6) scenario were realized, the general reduction in net payload would fall below $1 \%$. The primary driver for the near-surface air density changes is warming itself, but for some regional areas, the increase in water vapour holding capacity also is responsible. The reanalyses indicate that the near-surface air density decreases consistently predicted by global climate models are currently occurring, and as Fig. 2 shows, will continue for quite a while, as will the impact for the aviation industry.

\section{Conclusions}

In this brief contribution, based on diagnosis of stresses (and forces) exerted on aircraft, a suitable invariant entity was identified for investigating climate change effects on aviation payload. Assuming no changes in technical aspects of aircraft and no changes to FAA regulations on take-off performance, near surface air density is the single most significant atmospheric parameter. Reanalyses data indicated clearly that the Earth's atmosphere had expanded in volume in the past half century. Consequently, the near surface air density has experienced significant decreases globally. The 27 climate models showed a high level of consensus in simulated near surface air density variations. The ensemble mean of their twenty-first century simulations in NSAD trends was used to examine future reduction to effective payload. In line with Coffel and Horton (2015), our study illustrates the potential for rising temperatures to influence weight restriction at take-off stage. All technical aspects as commented on by Hane (2016) were assumed to be invariants during the analyses period. The simple fact that during extreme hot weather in summertime, cargo airplanes have to reduce the effective payload indicates the validity of such analyses. The difference found with seasonal cycle is that these superimposed effects work persistently year round and there is no easy way to circumvent or ameliorate them. We, however, agree with Hane (2016) that aviation industry still has technical room to cope with the detrimental effects from climate warming, perhaps at the extra costs of maintenance, passenger comfort, and perhaps relaxation of aviation code.

In contrast with the recent studies by Coffel and Horton (2015), the analyses here were based on near surface air density, a fundamental parameter for lift generation. The forces acting on aircraft during take-off stage all are proportional to near surface air density, making it an ideal 
measure for climate warming effects on civil aviation. More importantly, it is found that changes in near surface air density are not uniform globally, as shown for the past 50 years (e.g., from the reanalyses period) and as will likely also occur in the future (from examining climate model output). Temperature increase is not the only factor causing near surface density decrease. The associated water vapor and circulation adjustments make the issue non-local albeit a complicated one that deserves investigations using sophisticated climate model output. Different global regions are being impacted in a disparate way and regional fidelity becomes more valuable than global mean, which might be obtained by a rule of thumb. For example, it is rather counter-intuitive that vapour increase plays a significant role in decreasing surface density in some high latitude regional areas (e.g., oceanic areas off the southeast of Greenland). Only analyses based on output from coupled climate models can reveal such regional features with practical implications. The loss of effective load due to climate warming is already economically significant and there seems to be no sign of lessening. This is an emerging research field and our analysis only sets the basic rubrics for future detailed investigations.

Acknowledgements The author thanks Professors Mervyn Lynch for assistance in proof-reading the entire manuscript and for very helpful discussions on some of the issues. The lead-author also is thankful for Prof. Lynch for liaison to the Curtin-IAP MOU. We thank Dr Q. Duan (BNU) for useful discussion on climate impacts on various aspects of social economics, especially for developing countries. The research is supported by National Natural Science Foundation of China CNNSF funds (Grant no. 41475063 and 41775075) awarded to co-author W. Guo and a 6-month informal contract from Hohai University (through the Fundamental Research Funds for the Central Universities) to the leading author.

Table 1 Twenty-seven GCM models used in this study

\begin{tabular}{|c|c|c|}
\hline Model name & Institution & Horizontal resolution \\
\hline ACCESS1-0 & $\begin{array}{l}\text { Commonwealth Scientific and Industrial Research Organization } \\
\text { (CSIRO)/Bureau of Meteorology (BoM) }\end{array}$ & $192 \times 145$ \\
\hline ACCESS1-3 & CSIRO/BoM & $192 \times 145$ \\
\hline CCSM4 & National Center for Atmospheric Research & $288 \times 192$ \\
\hline CanESM2 & Canadian Center for Climate Modelling and Analysis & $128 \times 64$ \\
\hline CNRM-CM5 & Centre National de Recherches Meteorologiques & $256 \times 128$ \\
\hline CESM1-BGC & National Center for Atmospheric Research & $288 \times 192$ \\
\hline CESM1-CAM5 & National Center for Atmospheric Research & $288 \times 192$ \\
\hline FGOALS-g2 & Institute of Atmospheric Physics, Chinese Academy of Sciences & $128 \times 60$ \\
\hline GFDL-CM3 & Geophysical Fluid Dynamics Laboratory & $144 \times 90$ \\
\hline GFDL-ESM-2G & Geophysical Fluid Dynamics Laboratory & $144 \times 90$ \\
\hline GFDL-ESM-2M & Geophysical Fluid Dynamics Laboratory & $144 \times 90$ \\
\hline GISS-E2-H & NASA/Goddard Institute for Space Studies (GISS) & $144 \times 90$ \\
\hline GISS-E2-R & NASA/GISS & $144 \times 90$ \\
\hline HadGEM2_AO & $\begin{array}{l}\text { National Institute of Meteorological Research } \\
\text { Korea Meteorological Administration (S. Korea) }\end{array}$ & $192 \times 145$ \\
\hline HadGEM2_CC & Met Office Hadley Centre & $192 \times 145$ \\
\hline HadGEM2_ES & Met Office Hadley Centre & $192 \times 145$ \\
\hline INM & Institute of Numerical mathematics, Russian Academy of Sciences & $180 \times 120$ \\
\hline IPSL-CM5A-LR & Institut Pierre Simon Laplace (France) & $96 \times 96$ \\
\hline IPSL-CM5A-MR & Institut Pierre Simon Laplace (France) & $144 \times 143$ \\
\hline IPSL-CM5B-LR & Institut Pierre Simon Laplace (France) & $96 \times 96$ \\
\hline MIROC5 & Atmosphere and Ocean Research Institute, The Tokyo University & $256 \times 128$ \\
\hline MIROC-ESM & Japan Agency for Marine-Earth Science and Technology & $128 \times 64$ \\
\hline MRI-CGCM3 & Meteorological Research Institute & $320 \times 160$ \\
\hline MPI-ESM-LR & Max Plank Institute (MPI) for Meteorology & $128 \times 64$ \\
\hline MPI-ESM-MR & Max Plank Institute (MPI) for Meteorology & $192 \times 96$ \\
\hline NorESM1-M & Bjerknes Center for Climate research, Norwegian Meteorological Institute & $144 \times 96$ \\
\hline NorESM1-ME & & $144 \times 96$ global grids \\
\hline
\end{tabular}


Table 2 Actual payload equivalence of a $1 \%$ reduction in near surface air density

\begin{tabular}{|c|c|c|c|c|c|c|c|}
\hline Aircraft type & 1\% MTOW (kg) & Aircraft type & $1 \%$ MTOW $(\mathrm{kg})$ & Aircraft type & $1 \%$ MTOW $(\mathrm{kg})$ & Aircraft type & $1 \%$ MTOW $(\mathrm{kg})$ \\
\hline $\begin{array}{l}\text { Bombardier } \\
\text { (Bom) CS300 }\end{array}$ & 653.2 & $\begin{array}{c}\text { Antonov An- } \\
124-100 \mathrm{M}\end{array}$ & $4050.6(1.7 \%)$ & $\begin{array}{l}\text { Douglas DC-8- } \\
\quad 61\end{array}$ & 1474.2 & $\begin{array}{l}\text { McDonnell } \\
\text { Douglas } \\
\text { MD-90-30 }\end{array}$ & 707.6 \\
\hline $\begin{array}{l}\text { Vickers Vis- } \\
\text { count } 800\end{array}$ & $303.9(3 \%)$ & $\begin{array}{l}\text { Lockheed } \\
\text { L-1011-200 }\end{array}$ & 2113.7 & $\begin{array}{l}\text { Handley Page } \\
\text { Hermes }\end{array}$ & 390.1 & $\begin{array}{l}\text { de Havilland } \\
\text { (dH) Comet } 1\end{array}$ & 499.0 \\
\hline $\begin{array}{l}\text { Airbus A330- } \\
200\end{array}$ & $2300(1.97 \%)$ & B767-400ER & 2041.2 & B727-100 & 771.1 & Bom CS100 & 589.7 \\
\hline $\begin{array}{l}\text { Tupolev Tu- } \\
154 \mathrm{M}\end{array}$ & 1043.3 & Bom CRJ700 & 329.8 & MD-83 (2.2\%) & 725.7 & $\begin{array}{l}\text { Ilyushin IL-96- } \\
300\end{array}$ & 2499.3 \\
\hline A380-800 & $5443.1(1.9 \%)$ & Boeing 787-8 & 2279.3 & B707-120B & 1165.7 & A318 & 590.1 \\
\hline Boeing B747-8 & $4477.0(2 \%)$ & A350-1000 & 3079.9 & B707-320B & 1513.2 & B737-600 & 660.0 \\
\hline B747-400ER & 4127.7 & IL-86 & 2079.7 & B720B & 1061.4 & B737-400 & 679.0 \\
\hline B747-400 & 3968.9 & B767-300ER & 1868.8 & B727-200 & 838.2 & B737-300 & 628.2 \\
\hline B747-200 & 3778.4 & A $300-600 R$ & 1719.1 & HS Trident 2E & 646.4 & B717-200HGW & 548.8 \\
\hline B747-300 & 3778.4 & A300-600 [7] & 1632.9 & Caravelle III & 459.9 & B737-500 & 604.2 \\
\hline A340-200 & 2535.1 & B737-900ER & 851.4 & DC-6B & 485.3 & $\begin{array}{l}\text { Embraer ERJ } \\
145\end{array}$ & $220(3.6 \%)$ \\
\hline A340-500 & 3719.5 & A310-300 [7] & 1569.9 & dH Comet 2 & 544.3 & Embraer 190 & 477.6 \\
\hline B777-200LR & 3474.5 & A310-200 & 1416.6 & Convair 880 & 875.4 & Embraer 175 & 375.1 \\
\hline B747-100 & 3333.9 & $\mathrm{~A} 400 \mathrm{M}$ & 1409.8 & ATR 42-500 & 186.0 & Embraer 170 & 359.7 \\
\hline B777-300 & 2993.7 & B757-300 & 1236.0 & ATR 72-600 & 227.7 & Bom CRJ900 & 365.1 \\
\hline MD-11 & 2732.9 & B757-200 & 1156.7 & DC-4 & 331.1 & Bom Q400 & 279.9 \\
\hline Il-96M & 2698.9 & Tu-204SM & 1043.3 & DC-6 & 440.9 & Saab 2000 & 227.7 \\
\hline A350-900 & 2680.7 & A321-100 & 829.6 & DC-6A & 486.3 & Bom CRJ200 & 231.3 \\
\hline A340-600 & 3674.1 & the Concorde & 1850.7 & dH Comet 3 & 680.4 & B717-200BGW & 499.0 \\
\hline B777-300ER & 3515.3 & B767-300 & 1587.6 & dH Comet 4 & 707.6 & Fokker 100 & 458.1 \\
\hline $\mathrm{B} 777 \mathrm{~F}$ & 3478.1 & Vickers VC10 & 1518.6 & dH Hercules & 70.8 & Avro RJ-85 & 421.8 \\
\hline B777-200 & 2472.1 & B737-900 & 851.4 & DC-7 & 553.4 & A330-300 & 2120.1 \\
\hline A350-800 & 2590.0 & B737-800 & 790.2 & DC-8-32 & 1406.1 & B737-700 & 700.8 \\
\hline A340-300 & 2766.9 & A319 & 640.0 & DC-8-51 & 1251.9 & An-225 & 6400.2 \\
\hline B787-9 & 2508.4 & A320-100 & 679.9 & A380-800F & 5896.7 & B377 & 671.3 \\
\hline
\end{tabular}

The percentages of maximum payload equivalence are shown in parenthesis

Open Access This article is distributed under the terms of the Creative Commons Attribution 4.0 International License (http://creativeco mmons.org/licenses/by/4.0/), which permits unrestricted use, distribution, and reproduction in any medium, provided you give appropriate credit to the original author(s) and the source, provide a link to the Creative Commons license, and indicate if changes were made.

\section{Appendix}

See Tables 1 and 2.

\section{References}

Allen M, Ingram W (2002) Constraints on future changes in climate and the hydrologic cycle. Nature 419:224-232
Brasseur G, Gupta M, Anderson B, Balasubramanian S, Barrett S, Duda D, Fleming G, Forster P, Fuglestvedt J, Gettelman A, Halthore R, Jacob S, Jacobson M, Khodayari A, Liou K, Lund M, Miake-Lye R, Minnis P, Olsen S, Penner J, Prinn R, Schumann U, Selkirk H, Sokolov A, Unger N, Wolfe P, Wong H, Wuebbles D, Yi B, Yang P, Zhou C (2016) Impact of aviation on climate: FAA's aviation climate change research initiative (ACCRI) Phase II. Bull Am Meteorol Soc 97:561-583

Coffel E, Horton R (2015) climate change and the impact of extreme temperatures on aviation. Weather Clim Soc 7:94-102

Fichter C, Marquart S, Sausen R, Lee D (2005) The impact of cruise altitude on contrails and related radiative forcing. Meteorol Zeitschrift 14:563-572

Fu Q, Liou K (1993) Parameterization of the radiative properties of cirrus clouds. J Atmos Sci 50:2008-2025

Hane F (2016) Comment on "Climate change and the impact on extreme temperatures on aviation". Weather Clim Soc 8:205-206

Held I, Soden B (2006) Robust response of the hydrological cycle to global warming. J Clim 19:5686-5699

Holman J (1980) Thermodynamics. McGraw-Hill, New York pp217. 
IPCC (1999) Aviation and the global atmosphere-a summary for policy makers. Cambridge University Press, Cambridge, p 373

IPCC (2013) Understanding the climate system and its recent changes, in: summary for policymakers, in: IPCC AR5 WG1, IPCC, Geneva

Iwabuchi H, Yang P, Liou K, Minnis P (2012) Physical and optical properties of persistent contrails: Climatology and interpretation. J Geophy Res 117(D6):D06215

Khon V, Park W, Latif M, Mokhov I, Schneider B (2010) Response of the hydrological cycle to orbital and greenhouse gas forcing. Geophys Res Lett 37:L19705

Kistler R, Kalnay E, Collins W, Saha S, White G, Woollen J, Chelliah M, Ebisuzaki W, Kanamitsu M, Kousky V, van den Dool H, Jenne R, Fiorino M (2001) The NCEP-NCAR 50-year reanalysis: Monthly means CD-ROM and documentation. Bull Am Meteorol Soc 82:247-267

Lawrence M (2005) The relationship between relative humidity and the dew point temperature in moist air: A simple conversion and applications. Bull Am Meteorol Soc 86:225-233

Lewis S, Karoly D (2015) Are estimates of anthropogenic and natural influences on Australia's extreme 2010-2012 rainfall modeldependent? Clim Dyn 45:679-695

Minnis P, Schuman U, Doelling D, Gierens K, Fahey D (1999) Global distribution of contrail radiative forcing. Geophys Res Lett 26:13, $1853-1856$
Santer B, Sausen R, Wigley T, Boyle J, AchutaRao K, Doutriaux C, Hansen J, Meehl G, Roeckner E, Ruedy R, Schmidt G, Taylor KE (2003) Behavior of tropopause height and atmospheric temperature in models, reanalyses, and observations: Decadal changes. J Geophys Res 108(D1):4002. https://doi.org/10.1029/2002JD0022 58

Sausen R, Isaksen I, Grewe V, Hauglustaine D, Lee D, Myhre G, Köhler M, Pitari G, Schumann U, Stordal F, Zerefos C (2005) Aviation radiative forcing in 2000: an update on IPCC (1999). Meteorol Zeitschrift 14:555-561

Stuber N, Forste P, Radel G, Shine K (2006) The importance of the diurnal and annual cycle of air traffic for contrail radiative forcing. Nature 441:864-867

Taylor K, Stouffer R, Meehl G (2012) An overview of CMIP5 and the experiment design. Bull Am Meteorol Soc 93:485-498

Trenberth K (2011) Changes in precipitation with climate change. Clim Res 47:123-138

Wallace J, Hobbs P (2006) Atmospheric science, 2nd edn. Academic Press, Cambridge

Yi et al (2012) Simulation of the global contrail radiative forcing: a sensitivity analysis. Geophys Res Lett 39:L00F03 